\title{
Proposal of a new method for treating type II odontoid fractures: Odontoid process prosthetic (Ti)
}

\author{
Marc Johnston, Shawn Ranieri, and William de Wit
}

This manuscript was prepared for $\mathrm{HK}^{*} 4610$ Health and Injury Biomechanics under the supervision of Prof. Jim Dickey, Human Health and Nutritional Sciences, and submitted via Prof. John Runciman, School of Engineering.

\begin{abstract}
A novel method for treating type II odontoid fractures is presented. The use of a sintered titanium odontoid prosthetic could eliminate long healing times associated with external fixation methods, and the neurological deficits associated with non-union events in odontoid fracture treatment. Finite element experiments provide early indications that the axis vertebral body could accommodate a titanium odontoid prosthetic. Strain of $3.5 \%$ and stresses of up to $10.5 \mathrm{MPa}$ on the reamed opening of the axis vertebral body are considered as the local maximums. Conventional and emerging implant fixation and non-fouling techniques are also discussed.
\end{abstract}

$\mathrm{O}$ dontoid fractures account for 10 to 11 percent of all cervical spine injuries in adult populations. ${ }^{26}$ Type II odontoid fractures are the most difficult to treat and consist of more than $35 \%$ of all axis fractures. The non-union rate in bone matrix of type II odontoid fractures is the highest, with a mean of $28.4 \%(n=340) .{ }^{24}$ Type II odontoid process fractures have been increasing in frequency during the past few decades due to increased motor vehicle injuries. ${ }^{22}$ The majority of cervical spine injuries, occurring in younger patients, are a result of high bending and shear forces. The more powerful forces are a result of motor vehicle accidents, ski accidents and falls from considerable heights. ${ }^{36}$ Elderly patients that fall from a standing height onto the cranium are at risk of odontoid fracture due to low bone mineral density. ${ }^{37}$ Figure 1 illustrates the relationship of bone mineral density of the odontoid process with age.

The majority of severe cervical spine injuries result from an impact with the head. The head is forced to rapidly decelerate and the velocity of the torso causes the neck to adopt a hyperextended or hyperflexed posture. ${ }^{22}$ The atlas, as a result, causes sufficient shear forces to fracture the odontoid process from the axis. ${ }^{36}$ Subsequent degrees of displacement of the odontoid process can occur due to shear forces in combination with axial compressive forces. ${ }^{4}$ Many factors are associated with treatment and or fracture management such as the fracture line anatomy, degree of dislocation, patient's age, amalgamation of related injuries and general physical state. ${ }^{1}$ Existing methods of treatment for type II odontoid fractures range from collar immobilization, ${ }^{1}$ halo jacket immobilization ${ }^{36}$ and operative treatments such as posterior fusion $^{9,32}$ and screw fixation. ${ }^{20,29,32}$ Odontoid fractures have many different methods of treatment, which causes incongruities when discussing long-term prognosis of this type of spinal injury. ${ }^{1}$ This disagreement is born by the incidences of non-union at the fracture site. Estimations are as low as 4.8 percent and as high as 62.8 percent. . $^{17,44,48}$

Non-union rates cause other physiological concerns such as neurological deficits $(85.7 \% ; \mathrm{n}=14)$, reduced range of motion $(28.6 \% ; \mathrm{n}=14)$ and cervical stiffness $(35.7 \% ; \mathrm{n}=$ 14). ${ }^{36}$ Individuals that exhibit neurological deficits demonstrate delayed signs and symptoms subsequent to nonunion of the dislocated odontoid process. The deficits can be noticed between 6 and 120 months (mean of 32 months) after the original dislocation. ${ }^{11}$ Periods of immobilization vary depending on the severity of the injury and the amount of blood supplied to the fracture site. ${ }^{27}$ The average immobilization period is 12 weeks. ${ }^{36}$ The instability of the atlantoaxial articulation can be attributed to inappropriate management of the dislocation.

\section{Anatomy AND Pathology}

The axis (C2), also called the epistropheus, is the second vertebra of the cervical spine; it creates a pivot point between the head and neck. The strongest characteristic is a perpendicular process which is responsible for two distinct articulations. The first articulating surface comprises of an anterior surface which is oval in shape and in contact with the atlas (C1). The second articulating surface is a posterior surface which is in contact with the transverse ligament. ${ }^{23}$ Two distinct regions characterize the cervical spine; the occipitoatlantoaxial region $(\mathrm{C} 1-\mathrm{C} 2)$ and the sub-axial region (C3-C7). The focus of the reviewed literature is centered on the atlantoaxial articulation which is essentially the 


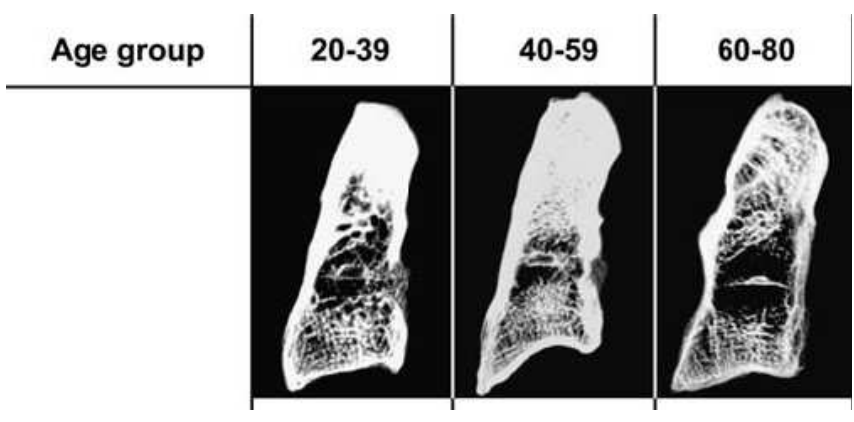

Figure 1: Bone matrix of odontoid process in three distinct age population using $x$-ray radiography. The level of chondroid matrix confirms a decreased bone mineral density with increased age. Figure adapted from Gebauer et al., 2006.

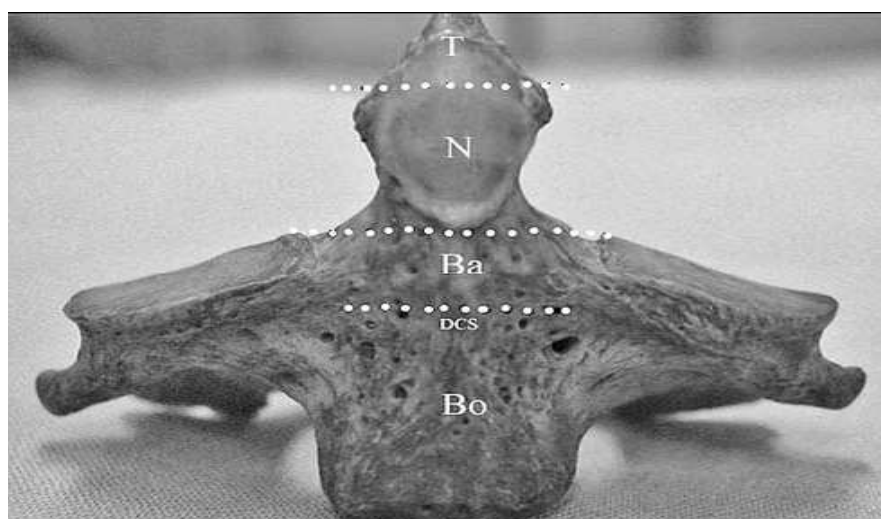

Figure 2: Axis vertebral body of a cadaveric specimen: $T$ tip of the odontoid, $N$ the neck of the odontoid, $B$ a the base of the odontoid and Bo the body of C2. Figure adapted from Çokluk et al., 2006.

occipitoatlantoaxial region. The atlantoaxial articulation is essential for keeping a normal lordotic spine posture. A lordotic alignment of the spine is accomplished through complex interactions between the vertebral bodies and integrated ligaments and muscles. This posture provides support to the cranium, protects vital neural pathways and allows for a wide range of motion. ${ }^{23}$

The odontoid process represents the foundation of stability at the atlantoaxial articulation due to the attached ligamentous structures. ${ }^{11}$ The ligamentous restraints in combination with the anterior atlantal arch provide support and prevent anterior-posterior dislocation. ${ }^{50}$ Type II odontoid fractures occur at the neck of the odontoid process located at the junction between the dens and the axis. Figure 2 shows the separate regions of the odontoid process. Due to the tendency of displacement, type II odontoid fractures are considered unstable. ${ }^{27}$ The odontoid process represents one third of the diameter of the spine canal, the spinal cord represents one third as well. The remaining third acts as a buffer region allowing for a degree of sublaxity or pathological displacement. ${ }^{50}$ When a type II odontoid fracture occurs, the fragment will be displaced along with the atlas due to the loss of support in the anterior-posterior direction. Severe displacements will cause compressive pressures to impinge on the spinal cord. This displacement will reduce the contact area of the fragments which will interfere with fracture union. ${ }^{11}$ The reliability of radiographs to demonstrate the contact area between fragments is not consistent. $^{46}$ To reduce incidences of non-union rates, a recommended maximal displacement of $20 \%$ in both planes dictates the recommended surface contact area of $64 \%$ or more. $^{11}$

M. R. Haffajee studied the arterial blood supply to the odontoid process as a possible factor explaining incidences of non-union of type II odontoid fractures. Three sources have been clearly defined as arterial blood supplies to the odontoid process. The first source is the anterior and posterior ascending arteries ${ }^{27}$ which are independent of the vertebral artery. ${ }^{49}$ The second source is found in the retropharyngeal cleft ${ }^{43}$ and consists of a pair of transverse arteries. The third source is an ascending pharyngeal artery. ${ }^{53}$ Fisher et al. in 1974 determined that the least vascularized region of the odontoid process seemed to be the neck; this can be correlated to the incidences of non-union in type II odontoid fractures. Therefore, theoretically, a fracture through the neck of the odontoid process causing sufficient displacement will interrupt the ascending arterial blood supply to the fracture site.

\section{Limitations of CuRRent Methods}

Type II odontoid fractures are the most frequent and recurring axis fractures that are consequently the most difficult to manage. ${ }^{24}$ Factors affecting the success of nonoperative management account only for odontoid process displacement and patient age. ${ }^{13}$ The non-union rate in nonoperative management is relatively high with a peak of $64 \% .^{54}$ When immobilization fails to keep adequate alignment, a revision surgery, such as posterior fusion and screw fixation, allow for correct alignment which renders the patient instantly mobile. The immobilization causes medical complications such as reduced range in motion, cervical stiffness and peripheral soft tissue damage. ${ }^{28}$ Henceforth fixation will reduce the medical complications from prolonged immobilization. ${ }^{31}$ The need for a more integrated approach to resolve issues concerning non-union rates and prolonged immobilization is essential for a better prognosis of type II odontoid fracture.

Roentgenographic and clinical factors such as patient age, ${ }^{2}$ degree of dislocation, ${ }^{14}$ direction of displacement, ${ }^{13}$ odontoid angulation of more than 10 degrees $^{7}$ and degree of neurological deficits ${ }^{13}$ have been researched to qualify the rate of non-union in type II odontoid fractures. Regardless of other associated factors, non-union of type II odontoid fractures seemed to be significant when the odontoid displacement was more than $6 \mathrm{~mm} .^{24}$ The integrity of the 
transverse atlantal ligament, in correlation with type II odontoid fracture, is also a factor affecting atlantoaxial stability. Even after posterior fusion and if the laxity in the transverse atlantal ligament is sufficient, stability will be affected, or "and will impinge on" impinging on the union at the fracture site. ${ }^{24}$ This finding directly relates to the delayed instability and non-union of cases involving odontoid angulation greater than 10 degrees, large displacement, and instability at the fracture site associated with poor immobilization. Therefore most odontoid fractures with associated ligament injuries should be managed with an early surgical method. ${ }^{12}$ A review of the current literature presents the differences between surgical and non-invasive treatments of type II odontoid fractures but fails to identify a recommended treatment. Therefore a distinct and appropriate treatment method remains controversial. The non-invasive methods of treatment presented limitations due to high rates of non-union and long periods of immobilization. The surgical approach of internal fixation presents many complications such as soft tissue injuries and nerve damage which can require revision surgeries. ${ }^{5,15,20,32}$ The posterior fusion technique can cause loss in lordosis of the cervical spine which causes abnormal forces within the entire cervical spine. ${ }^{33}$ An improved treatment method is also needed to reduce incidences of post-operative complications and revision surgeries. The introduction of a titanium odontoid prosthesis would reduce the rate of non-union and immobilization periods, and could reduce the neurological deficits associated with non-union.
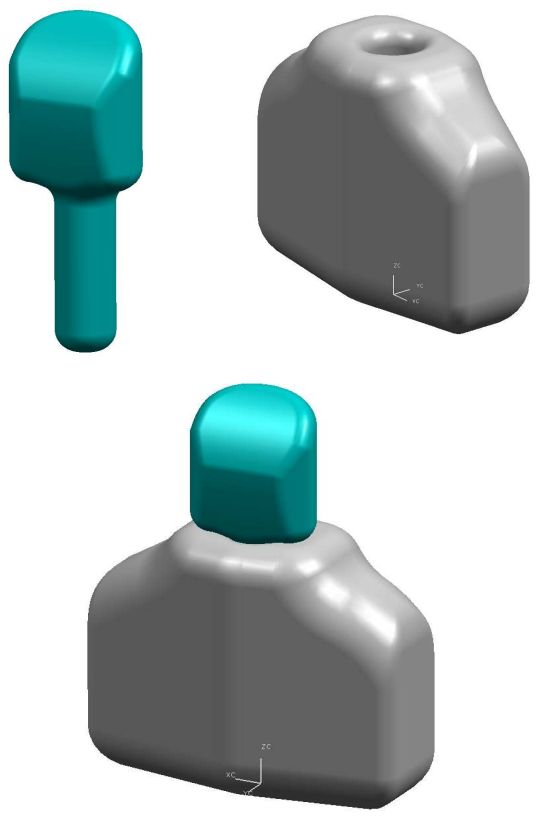

Figure 3: Top left - titanium dens. Top right - model of axis body segment (bone). Bottom - axis body segment and dens replacement assembly.

\section{IMPLANT DESIGN \& Finite ElEMENT Modeling}

A replacement dens was designed and modeled in UGS NX 4.0. It was composed of a head piece attached to a shaft that is meant to be inserted into the axis vertebral body shown in Figure 3. Only the segment interacting directly with the axis vertebral body is modeled as shown in the top left.

The head of the implant was contoured to simulate the anterior face of the dens extension and act to replace the articulating surface against the posterior tubercle of the atlas. The shaft was designed as a cylindrical extension with blended edges to maximize the bone-metal interface for fixation by bone ingrowths or cement (Polymethylmethacrylate, PMMA).

Basic dimensions like height, width and diameter that were chosen from anatomical measurements of the odontoid process that can be found in Morphometric Anatomy of the Atlas and Axis Vertebrae. The major dimensions of the implant may vary to fit to a specific individual. This design was modeled about the mean dimensions of the odontoid process. The shaft diameter was designed so that the implant would be structurally sound while leaving enough bone mass around it for the vertebral body to bear the load. The ability of the axis body to support the implant during physiological loading was the main concern for the design.

The replacement of biological tissue with isotropic engineering material always generates structural compatibility questions in prosthetic design. The titanium implant, with a high Young's modulus, can be assumed to transmit most of the force acting on it directly to the surrounding bone. A finite element model of the surrounding axis body was created and simulated forces were applied to it to test if the bone would fail from full extension of the neck. Figure 3 shows the model of the segment of the axis body surrounding the prosthetic.

The properties of bone, including modulus of elasticity, Poisson's ratio, density and ultimate strength were applied to the model. An integrated modulus of $2 \mathrm{GPa}$ (averaging cortical and trabecular bone together), Poisson's ratio of 0.3 and an ultimate tensile strength of $35 \mathrm{MPa}$ were used. ${ }^{47} \mathrm{An}$ integral bone density of $1087 \mathrm{~kg} / \mathrm{m}^{3}$ was used for the whole part. ${ }^{8}$ Integral values of the modulus and density were used to simplify the finite element model so that a cortical shell and trabecular body would not have to be assembled to ease simulation difficulty. Forces of $100 \mathrm{~N}$ acting at 45 degrees on the dens (physiologic loading at full extension ${ }^{21}$ ) were simulated as a couple applied to the opening and column of the reamed hole of the axis body segment. This segment was constrained by making the areas that were cut from the rest of the axis bone fixed.

The entire model was meshed using a unit size of 1 with 3D tetrahedrons. The model was solved using the UGS NX Nastran iterative solver and the results of stress and strain were recorded from the solution of 26589 tetrahedral elements and 41163 nodes. Figure 4 illustrates the loading 
scenario applied to the axis body in the finite element model and Figure 5 shows the tetrahedral meshing.

The magnitude of stress and strain can be seen by the colour map displayed in Figures 6 and 7 respectively. The maximum stress occurred at the fixed faces of the part, which was expected. A value of about $29 \mathrm{MPa}$ was resolved at the edge of the face. More importantly, the maximum stress around the reamed hole was about 10.5 MPa. Both of these values fall below the expected ultimate strength of the axis vertebrae, from 30 to $40 \mathrm{MPa}^{47}$ Similar results were found for the strain on the axis body with a maximum value of $12 \%$ at the fixed surface and $3.5 \%$ at the reamed opening.

The high values of stress and strain that occurred on the constrained faces can be attributed to the fact that they were statically fixed in the finite element model. These results would not be expected if the part was modeled as a continuous and complete axis vertebral body. The values of $3.5 \%$ strain and $10.5 \mathrm{MPa}$ on the reamed opening are considered as the local maximums on the axis body. These results show that using a metal implant embedded by this bone, under the specified dimensions, will exert tolerable stresses and strains on the apparatus under physiological loading.

Although the above analysis justifies the use of a metal implant on the axis vertebrae, it can easily be scrutinized by reasoning addressed later as recommendations for further investigation.

\section{Transverse Ligament and Bone Contact SURFACES}

It was necessary to develop a method of maintaining minimal tissue adhesion to the exposed regions of the implant because of the nearly constant contact that the implant makes with the transverse ligament, as well as contact with the atlas bone. We propose an original and highly experimental way of

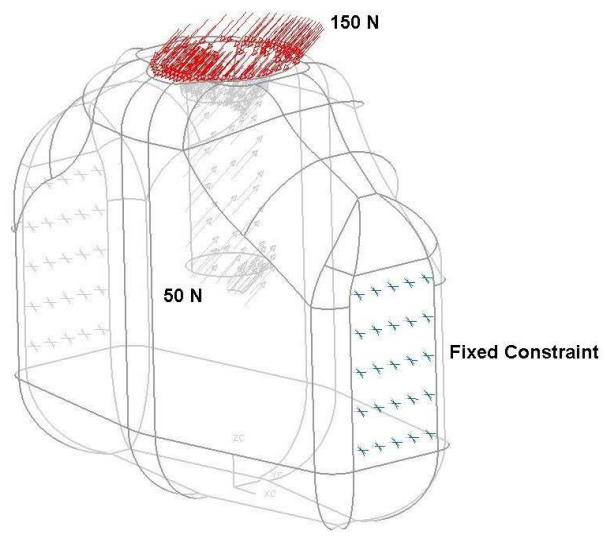

Figure 4: Boundary conditions on axis body finite element model. achieving prosthetic surface non-fouling, using what in nature (recently also in medical purposes) actually binds metals to living tissue. It is thought that the chemical used by mussels to anchor to metal, rock and other surfaces underwater can be used for surface non-fouling purposes. ${ }^{39}$

The compound called 3, 4-dihydroxyphenyl-L-alanine, or DOPA as it will be abbreviated below, is found in relatively high concentration in a unique protein mixture that is secreted by aquatic invertebrates. It is what seems to be ultimately responsible for the adhesion characteristics of mussel adhesive proteins, or MAP's. ${ }^{10}$

The DOPA is used to anchor PEG (polyethylene glycol) onto metal surfaces. This causes the metal surfaces to be resistant to cell adsorption. ${ }^{10}$ The mechanics by which MAP chemicals adhere to surfaces is not very well understood. It is thought to be a result of the catechol side chain of DOPA interacting with the surface substrate metal ions as well as certain polymer surfaces. ${ }^{55}$ DOPA containing peptides and PEG conjugate mPEG-DOPA 5K, and the analogue decapeptide derivative mPEG-MAPD 5K, were the two most effective compounds that were developed as non-fouling coatings for metal surfaces. ${ }^{10}$

The mPEG-MAPD 5K and mPEG-DOPA 5K use the same principal of MAP to bind to the oxide layer of a titanium substrate and then immobilize PEG molecules on the opposite surface. $^{16}$

The PEG molecules, now bound to the outer surface, provide resistance to protein and cell adherence of the implant. Titanium surfaces coated with mPEG-DOPA $5 \mathrm{~K}$ and mPEG-MAPD 5K have been shown in preliminary tests to eliminate fibroblast adhesion for over 14 days where the material is exposed to fresh cells twice every 7 days. ${ }^{10}$ The surface is designed with fitting contours on the exposed region of the implant that should reduce the likelihood of creating cracks in the atlas bone and provide a smooth surface for the transverse ligament.

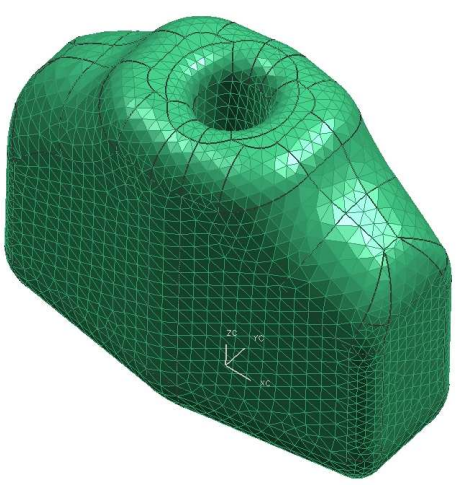

Figure 5: Tetrahedral mesh of axis body segment FE model (26589 elements, 41163 nodes). 

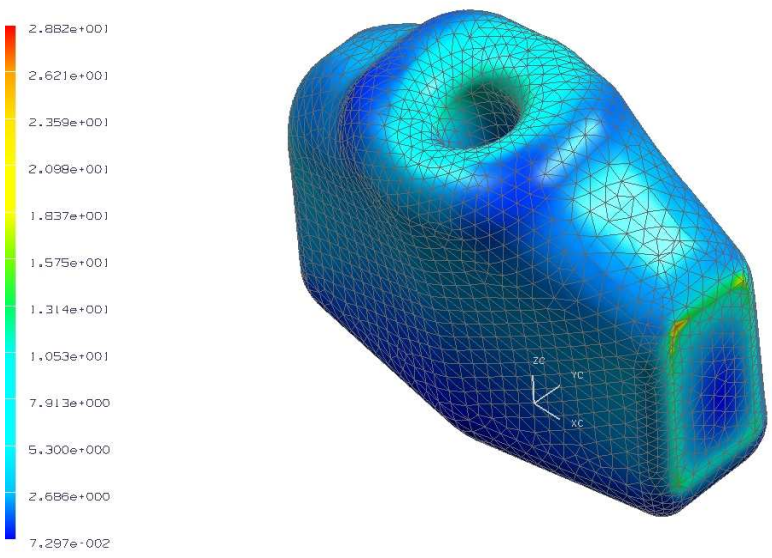

Figure 6: Stress distribution of axis body under simulated physiological loading (full extension).

\section{IMPLANT FIXATION}

The surgeon is required to ream out a hole in the axis (C2) where the prosthetic will be inserted. This ream must be done to specification with respect to the particular prosthetic, as the size and depth of insertion of the prosthetic will vary between individuals. The surgeon can then fix the prosthetic in place with the use of PMMA (Polymethylmethacrylate), the most common bone cement solution, ${ }^{30}$ or the region of the prosthetic inserted into the bone can be sintered to encourage bone ingrowths. ${ }^{41}$

Titanium was chosen as the material to be used for our dens replacement. Kuroda et al. in 1989, Seah et al. in 1998 and Ozaki et al. in 2001 stated that titanium has a high resistance to corrosion, is very inert under physiologic conditions and has high strength to weight ratio, making it the ideal material for our design. ${ }^{41}$

The advantages of using PMMA include very rapid curing times which lead to very short periods of time where atlantoaxial immobilization needs to take place in order to be certain the prosthetic is ready to bear load. Immobilization can be achieved with either conventional external immobilization, or with Herbert screws with or without wire fixation. The overseeing surgeon must decide which method of immobilization is the most appropriate depending on the patient. The major disadvantage of using PMMA is that the curing reaction generates heat and can induce crack propagation from residual stresses that are caused by curing. ${ }^{40}$ Therefore to avoid necrosis of the surrounding bone, it is important that the axis is properly reamed out to specification for the particular dimension of the prosthetic, and ensure that no cracks in the axis bone exist from the injury. Evenly spreading the cement around the surface of the reamed opening that contacts the prosthetic is crucial to
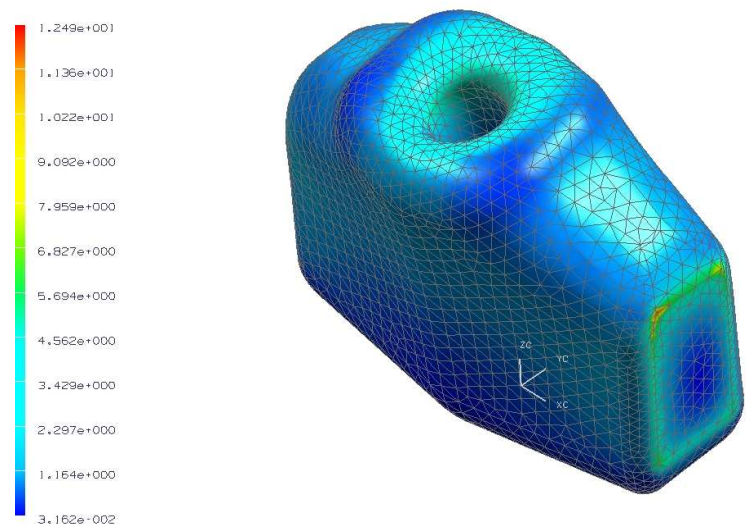

Figure 7: Strain distribution on axis body under physiological loading (full extension).

minimize heat generation during the curing process. Another disadvantage of using PMMA to secure the prosthetic is the potential of having to re-secure it if the cement fails over time. The risks involved with the use of PMMA are, as with most cemented implants as previously mentioned, revision or migration of the prosthetic, polymerization setting problems due to crack propagation, heat generation, infection and fever. The potential for rejection reactions also needs to be considered. $^{52}$

Bone ingrowth is another potential fixation method. Sintering is a form of powder metallurgy that creates a threedimensional layered porous matrix into which bone and soft tissue penetration can occur. ${ }^{42}$ If the region of the prosthetic that is inserted into the reamed axis opening is sintered, it will allow the adjacent bone surfaces to grow into the device, securing it. A big problem with fixation by bone ingrowth is the difference in elastic modulus between the bone and the prosthetic material. This difference is usually very large, for titanium alloys up to 10 times larger. ${ }^{41}$ This causes a phenomenon known as stress-shielding where the material with the larger elastic modulus does not distribute the stress to adjacent materials effectively and will cause the bone to remodel in response to the lack of stress applied to it. ${ }^{35}$ It has been found that the greater the sintered volume of a prosthetic, the better it is able to minimize stress shielding. This is because sintered regions of prosthetics demonstrate a reduced elastic modulus that reduces stress shielding and increases the life of the implant. ${ }^{41}$ A problem with surface coatings such as sintering is that they can result in insufficient surface mechanical integrity of the implant. This could potentially release foreign particles into the body if surface material breaks away. Migration of surface coating on the implant can also cause additional wear or stress concentrations within the implant. ${ }^{51}$ 


\section{CONCLUSION AND RECOMMENDATIONS}

Further experiments should model the entire axis vertebrae. This will shine light on the true effect of a titanium implant on the axis body and will likely remove the observed localized stress fields at the extremities of the model presented here. The mass density of cortical and trabecular bone of the vertebrae should be determined experimentally and modeled accordingly. The specific material properties of vertebral bone should be modeled as non-constant and anisotropic.

Another important recommendation is the investigation of the percent volume of sintering required to mimic the elastic modulus of bone while maintaining appropriate stiffness and strength as needed. This will significantly reduce stressshielding that may cause fracture of the axis body or failure of the implant. Adequate dispersion of stresses throughout the prosthesis and axis combination is critical in order to better cope with the everyday cyclic loading scenarios of the cervical spine. Maintaining the odontoid contact surfaces with the atlas vertebra and transverse ligament is another area of interest for research. The transverse ligament must maintain contact with the prosthesis with minimal cell adherence and ideally without the use of composite materials.

Although much work still needs to be done, the use of a titanium odontoid prosthetic is a promising vision, the ultimate objective of which is to eliminate long healing times associated with external fixation methods, and the neurological deficits associated with non-union events in odontoid fracture treatment.

\section{REFERENCES}

1. Anderson LD, D'Alonzo RT. Fractures of the odontoid process of the axis. J Bone Joint Surg (Am) 1974; 56: 16631674.

2. Apuzzo MLJ, Heiden JS, Weiss MH, Ackerson TT, Harvey JP, Kurze T. Acute fractures of the odontoid process: An analysis of 45 cases. J Neurosurg 1978;48:85-91.

3. Aymes, E. W., and Anderson, F. M.: Fracture of the Odontoid Process. Arch. Surg., 1956; 72: 377-393

4. Blauth M, Richter M Kiesewetter B, Lange U. Operative versus non operative treatment of odontoid non unions. How dangerous is it not to stabilize a non union of the dens? Chirurg, 1998; 70:1225-1238.

5. Borne GM, Bedou GL, Pinaudeau M, Cristino G, Hussein A (1988) Odontoid process fracture osteosynthesis with a direct screw fixation technique in nine consecutive cases. J Neurosurg 68: 223 \pm 226 .

6. Bruce, L., Chao, C., Nunallee, F., Motan, E., Shull, K., Messersmith, P. 2005. Rapid Gel Formation and
Adhesion in Photocurable and Biodegradable Block Copolymers with High DOPA Content. Macromolecules. 39: 1740-1748.

7. Clark CR, White AA III. Fractures of the dens: A multicenter study. J Bone Joint Surg [Am] 1985;67:1340-8.

8. Cody D., Divine G.W., Nahigian K., Kleerekoper M. 2000. Bone density distribution and gender dominate femoral neck fracture risk predictors. Skeletal Radiology. Vol: 29, pp 151-161.

9. Coyne TJ, Fehlings MG,Wallace MC, Bernstein M, Tator $\mathrm{CH}$. C1-C2 posterior cervical fusion: long-term evaluation of results and efficacy. Neurosurgery 1995;37:688-93.

10. Dalsin J., Huang Hu, Bi, Lee, B. Messersmith, P. 2003. Mussel Adhesive Protein Mimetic Polymers for the Preparation of Nonfouling Surfaces. American Chemical Society. 125: 4253-4258.

11. Dai, L. Y., Yuan, W., Ni, B., Liu, H. K.,. Jia, L. S, Zhao, D. L., Xu, Y. K.: Surgical treatment of nonunited fractures of the odontoid process, with special reference to occipitocervical fusion for unreducible atlantoaxial subluxation or instability. Eur Spine J., 2000; 9 :118122.

12. Dickman CA, Sonntag VKH, Papadopoulos SM, Hadley MN. The interspinous method of posterior atlantoaxial arthrodesis. J Neurosurg 1991;74:190-8.

13. Dunn ME, Seljeskog EL. Experience in the management of odontoid process injuries: An analysis of 128 cases. Neurosurgery 1986;18:306-10.

14. Ekong CEU, Schwartz ML, Tator CH, Rowed DW, Edmonds VE. Odontoid fracture: Management with early mobilization using the halo device. Neurosurgery 1981;9:631-7.

15. Etter C, Coscia M, Jaberg H, Aebi M (1991) Direct anterior fixation of dens fractures with a cannulated screw system. Spine 16 [Suppl] 3: S25 \pm 32 .

16. Fan X., Lijun L., Messersmith P. 2005. Surface-initiated polymerization from $\mathrm{TiO} 2$ nanoparticle surfaces through a biomimetic initiator: A new route toward polymermatrix nanocomposites. Composites Science and Technology. 66: 1195 - 1201.

17. Feilding, J. W.: Normal and Selected Abnormal Motion of the Cervical Spine from the Second Cervical Vertebra to the Seventh Cervical Vertebra Based on Cineroentgenography. J. Bone and Joint Surg., 1964; 46A: 1779-1781.

18. Fischer, L.-P., J.-P. Carrett, G.-P. Gonan and Y. Sayfi $1974 \mathrm{La}$ vascularisation arterielle de l'axis. Bull Assoc. Anat. (Nancy): 60:335-345.

19. Gebauer, Lohse, Barvencik, Pogoda, Rueger, Püschel, Amling. Subdental synchondrosis and anatomy of the axis in aging: a histomorphometric study on 30 autopsy cases. Eur Spine J., 2006; 15: 292-298. 
20. Geisler FH, Cheng C, Pokra A, Brumback RJ. Anterior screw fixation of posteriorly displaced type II odontoid fractures. Neurosurgery 1989;25:30-8.

21. Graham R.S., Oberlander E.K., Stewart J.E., Giffiths D.J. 2000. Validation and use of a finite element model of $\mathrm{C} 2$ for determination of stress and fracture patterns on anterior odontoid loads. Journal of Neurosurgery: Spine. Vol: 93.

22. Grauer, Jonathan N., Bilal Shafi, Alan S. Hilibrand, James S. Harrop, Brian K. Kwon, John M. Beiner, Todd J. Albert, Michael G. Fehlings, Alexander R. Vaccaro. Proposal of a modified, treatment-oriented classification of odontoid fractures. The Spine Journal, 2005; 5: 123129.

23. Gray, H., 1905, Gray's Anatomy. 6th Edition. East Molesey: Senate.

24. Greene KA, Dickman CA, Marciano FF, Drabier JB, Hadley MN, Sonntag VK. (1997) Acute axis fractures. Analysis of management and outcome in 340 consecutive cases. Spine 22:1843-1852.

25. Greene KA, Dickman CA, Marciano FF, Drabier J, Drayer BP, Sonntag VKH. Transverse atlantal ligament disruption associated with odontoid fractures. Spine 1994;19:2307-14.

26. Hadley MN, Browner CM, Liu SS, Sonntag VK (1988) New subtype of acute odontoid fractures (type IIA). Neurosurgery 22(1 Pt 1):67-71.

27. Haffajee, M.R., A Contribution by the Ascending Pharyngeal Arteryto the Arterial Supply of the Odontoid Process of the Axis Vertebra. Clinical Anatomy, 1997; 10:14-18.

28. Hanigan WC, Powell FC, Elwood PW, Henderson JP. Odontoid fractures in elderly patients. J Neurosurg 1993;78:32-5.

29. Harms J, Melcher RP. Posterior C1-2 fusion with polyaxial screw and rod fixation. Spine 2001;22:246771.

30. Harper E. Bioactive Bone Cements. 1998. Proceedings of the Institution of Mechanical Engineers - Journal of Engineering in Medicine. 212: Part H..

31. Heller JG, Viroslav S, Hudson T. Jefferson fractures: The role of magnification artifact in assessing transverse ligament integrity. J Spinal Disord 1993;6:392-6.

32. Jeanneret B, Mageral F. Primary posterior fusion $\mathrm{C} 1 / 2$ in odontoid fractures: indications, technique, and results of transarticular screw fixation. J Spinal Disord 1992;5:464-75.

33. Jeanneret B, Vernet O, Frei S, Magerl F (1991) Atlantoaxial mobility after screw fixation of the odontoid: a computed tomographic study. J Spinal Disord 4: 203 \pm 211 .

34. Jeffrey Lawrence Dalsin. Mussel Adhesive-Inspired Surface Modification for the Preparation of Nonfouling Biomaterials. Northwestern University. Evanston, Illinois. December 2004.
35. Joshi M, Advani S, Miller F, Santare M. 2000. Analysis of a femoral hip prosthesis designed to reduce stress shielding. Journal of Biomechanics. 33: 16551662.

36. Komadina, R., Brilej, D., Kosanović, M., Vlaović, M., Halo jacket in odontoid fractures type II and III. Arch Orthop Trauma Surg 2003; 123 : 64-67.

37. Komadina R., Osteoporotic fractures. Slovenian Society of Trauma Surgeons, 1999; 21-30.

38. Kuwahara H, Mazaki N, Takahashi M, Watanabe T, Yang X, Aizawa T. 2001. Mechanical properties of bulk sintered titanium nitride ceramics. Materials Science and Engineering. A319-321: 687-691.

39. Lee B, Chao, C, Nunalee,F. Motan, E. Shull, K. Messersmith,B. Rapid Gel Formation and Adhesion in Photocurable and Biodegradable Block Copolymers with High DOPA Content http://biomaterials.bme.northwestern.edu/Papers/ma051 8959.pdf Accessed November 23, 2006.

40. Lennon A., Prendergast P. 2002. Residual stress due to curing can initiate damage in porous bone cement: experimental and theoretical evidence. Journal of Biomechanics. 35: 311-321.

41. Oh I, Nomura N, Masahashi N, Hanada S. 2003. Mechanical Properties of porous titanium compacts prepared by powder sintering. Scripta Materialia. 49: 1197-1202.

42. Oliveira M, Pereira L, Cairo C. 2002. Porous Structure Characterization in Titanium Coating for Surgical Implants. Materials Research. 5:3 269-273.

43. Parke, W.W. 1978 The vascular relations of the upper cervical vertebrae. Orth. Clin. of North America 9:879_ 889.

44. Roberts, A., and Wickstrom, J.: Prognosis of Odontoid Fractures. In Proceedings of The American Academy of Orthopedic Surgeons. J. Bone and Joint Surg. 1972; 54A: 1353.

45. Rogers, W. A. : Fractures and Dislocations of the Cervical Spine. An End-Result Study. J. Bone and Joint Surg., 1957; 39-A: 341-376.

46. Ryan MD, Taylor TKF (1982) Odontoid fractures: a rational approach to treatment. J Bone Joint Surg Br 64 : 416-421.

47. Sadegh A.M., Tchako A. 2000. Vertebral stress of a cervical spine model under dynamic load. Technology and Health Care. Vol: 8, pp143-154.

48. Schatzker J, Rorabeck CH,Waddell JP. Fractures of the dens (odontoid process): an analysis of thirty-seven cases. J Bone Joint Surg 1971; 53B:392-405.

49. Schiff, D.C.M. and W.W. Parke 1973 The arterial supply of the odontoid process. J. Bone Jt. Surg. 55A:1450-1456.

50. Steel HH (1968) Anatomical and mechanical considerations of the atlantoaxial articulations. J Bone Joint Surg Am 50:1481-1482. 
51. Taksali S, Grauer J, Vaccaro A. 2004. Material considerations for intervertebral disc replacement implants. The Spine Journal. 4: 231S-238S.

52. U.S. Department of Health and Human Services Food and Drug Administration Center for Devices and Radiological Health. Class II Special Controls Guidance Document: Polymethylmethacrylate (PMMA) Bone Cement; Guidancefor Industry and FDA.

53. Williams, P.L. and R.Warwick (eds.) 1990 Gray's Anatomy, 36th ed. London: Churchill Livingstone, p. 678.

54. Schatzker J, Rorabeck CH, Waddell JP. Fractures of the dens (odontoid process): An analysis of thirty-seven cases. J Bone Joint Surg [Br] 1971;53:392-405.

55. Yu M., Hwang J., Deming, T. J.1999. American Chemical Society. 121: 5825-5826.

56. Zhang H., Bai J. 2005. Nonlinear Finite Element Analysis of C0-C1-C2 Complex under Physiologic Loads. In Proceedings of the 2005 IEEE Engineering in Medicine and Biology 27th Annual Conference. Shanghai, China. 